\title{
The Teaching System Research Of Digital Media Courses In The Design Of Visual Communication
}

\author{
Xue Bai ${ }^{1}$, Jiabei Liu ${ }^{1}$, Xiaozhang Zhang ${ }^{1}$ \\ ${ }^{1}$ School of Art and Design,Wuhan University of Science and Technology, Wuhan, China
}

Keywords: Visual, Communication design, Digital media, Teaching system.

\begin{abstract}
With the development of information technology, people familiar with and master the information of digital transmission. Digital media technology professional is numerous colleges and universities students. In the digital media technology professional, visual communication design education reform not only should have new knowledge content, but also has a new form of knowledge; visual communication design has become a more elements, the design of the multi-disciplinary cross discipline direction. Actively adapt to the development of the digital age, information transmission, grasp the visual communication as the main form of digital media era of information dissemination characteristics, from digital media environment of the change of the mode of people receiving information, this paper explore the visual communication design innovation and practice in curriculum system.
\end{abstract}

\section{Introduction}

With the development of information technology, more and more people to know and master the information of digital transmission, it becomes the inevitable trend of social development. Professional digital media technology is one of the hotspot in professional colleges and universities in our country in recent years. However, the domestic some unclear understanding of the system of the major colleges and universities, professional direction set generalization, curriculum platter, the bachelor of applied education cannot meet the needs of society. It is understood that in recent years, the business enterprise inside the art talents and technical talents appeared some problems in the cooperation, brings difficulties to work. Therefore, it is particularly important to improve the students' art accomplishment. Visual communication designs belong to the category of art and design, it is relatively close and digital media technology cooperation areas, cross between them and compound. Social development requires innovation, more in need of innovation education in colleges and universities. Visual communication design which is based on digital media technology breaks through the original design concept, to pay attention to the interactive art design of the user experience, relate clever art and technology. Break through professional limitations, therefore, integration of professional fields, on this particular digital media technology professional development is essential. To innovate in teaching, must first to reform the curriculum, secondly to innovation of teaching methods.

\section{Digital media environment that the morphology of visual communication design and cultural significance}

With consumption ideas are from the material consumption to the spirit of conversion, digital media has created a new concept of cognitive world, people in the era of digital media, represented by digital technology, digital media, the speed, quantity, and great changes have taken place in spreading information, digital visual technology development and propagation characteristics of the media, the change and change, vision, as the most direct factors perception, research on digital media, the visual language is extremely necessary. In this paper, in view of visual communication design as the main characteristic, according to the research status at home and abroad as a visual communication research based on digital media environment, analyses the development trend of visual 
communication, and put forward reasonable suggestion and the development direction, to improve the development of visual communication patterns, attitudes to visual communication design is no longer meet the basic functions, and more hope that work can be more personalized and humanized, in short, is to mobilize all the elements, to achieve the purpose of accurate visual transmission, give people a visual psychological satisfaction, which leads to the future development trend of visual communication design.

Visual communication design concept. Visual communication design is for people to achieve a certain purpose in a planned way of design, the design image and the way of delivery, a large number of studies have shown that accounts for two-thirds of the way people pass information in vision, so the development of visual communication design, the research direction is the interaction between people, in terms of the senses, the analysis method of propagation direction as the information is correct, will the plane design way of development to a certain degree of conversion, this way of visual communication design is mainly by visual signal is passed to the other side of the content of the food to express, "visual communication vision is based on science and technology as the means, art design, in the form of type", the main characteristics of visual communication design is: in terms of the overall digital language information, fast speed, wide mode, the characteristics of the transmission distance.

The connotation of digital media. Under the digital media is a new technical support system of media forms, such as magazines, newspapers, radio, mobile phone short message,. Relative to the newspapers, radio, outdoor, television, the four traditional media, digital media is vividly called the "fifth media". According to the technical division, that can be divided into two categories: one is the traditional media, digital, such as digital newspapers, magazines, etc. Second, it is under the new technology of media, such as mobile TV network, digital TV, movie, touch media and so on. In digital media technology, mode of transmission, forms, visual language on the rendering changes and breaks through than ever before. Due to the influence of digital media technology, the expansion of the visual communication design needs to be bigger, such as interactive entertainment design, multimedia design, network structure, application software, interface design and the design of the digital equipment, from a single perspective of two-dimensional space is expanded to many aspects of three-dimensional space, four dimensional space, even make visual communication a wider space.

\section{Visual communication design education present diversified development trend}

Under the economic development, knowledge level, people's life in improving at the same time, under the action of different ways, and the environment of digital media, electronic information, people can use computer to interact between people, between man and machine is particularly prominent, the digital media environment, people use of visual communication design to create some new design, relative to the original visual communication design, digital media environment of visual communication design in the different aspects of the development provides a new research direction, such a design more tend to diversify. This new way is mainly used in high-tech and advanced visual communication mode, virtualization of express way can better communication, when entering a new development trend in terms of visual integrated has been improved, so as to further perfect information.

Development trend of visual communication design in digital media environment. Digital media environment is the development of information technology and the rise of social economy, the inevitable outcome of the development of the common progress of the human environment is the rapid development of digital information technology, digital image, a variety of images, the rise of the network technology, communication technology, make the information transmission can be implemented under a variety of ways and the progress of the society, also prompted media rapid development, information technology and new high-tech comprehensive means such as multimedia design, make the traditional visual communication design broke the previous plane, static propaganda effect, with the visual effect of diverse, rapidly convey all kinds of information, the development of informatization has become inevitable trend of contemporary design, it will completely change people's habits and customs, value orientation, aesthetic temperament and interest, force us to set up 
the correct visual communication design of new ideas, new ideas and new methods. Lingering digitization becomes the contemporary design development trend.

Digital media environment's influence on the visual communication design. The development of visual communication design, and promote the transformation of plane graphic design to three-dimensional graphics process, $2 \mathrm{~d}$ graphics to $3 \mathrm{~d}$ or $4 \mathrm{~d}$ transformation. Design as a kind of concept art, digital media environment of visual communication design is to add a new design concept and the new design soul, make it more creative vitality. In digital media environment, visual communication design is no longer the past simple business, but rather reflect more innovative consciousness of main body, so that the art and visual communication design more personalized, better realize the information, make visual communication design become the backbone of the creative industries, with the development of science and technology and the progress of information technology, digital media own development at the same time, also promote the development of visual communication design, under the environment of digital media, visual communication design have more free space, its also began moving into the direction of diversification, along with the modern people's pursuit of new things more and more intense, more and more open, the diversity of visual communication design diversified development has become the sign of The Times of science and technology, but we need to pay attention to that the diversity of visual communication design and the development of the diversified development is not arbitrary, it is the creative diversity and diversification, the more is the embodiment of the creative, for the different needs of people can bring different requirements. Diversified variety trend of the development of visual communication design, convey to the development of digital media to provide more reliable conditions.

Visual communication design education new idea and new space. Sleep communication education in the process of the development of China's more than 20 years, changing roles, from packaging design, graphic design and visual communication design. The end of the 20th century, digital media, qualitative changes have taken place in social environment, the diversity of visual concepts herald a new way of visual communication is going to break the limits of traditional design category, make visual communication design a can fuse the carrier of a variety of disciplines.

Visual communication design education and multidisciplinary cross development. Visual communication design is more than one element, the design of the multi-disciplinary cross discipline direction. Establishment of visual communication design corresponding professional orientation, is the need of the healthy development of design art. The arrival of the digital age, visual communication design has its unique connotation and form of expression, on the one hand, to promote the combination of new technology and traditional art and design, highlight the design characteristics of The Times and rich connotation, on the one hand, want to combine the new technology to open up new research field, new media art design for the subject gives new content, reflect the prospective of visual communication design theory and method, a comprehensive update of visual communication design course system, promote and promote the development of visual communication design education.

\section{The application of visual communication design in curriculum innovation}

Visual communication design education reform in the end to put in for the construction of curriculum system, teaching method reform and innovation of comprehensive experimental courses. Comprehensive experimental courses should be run through the visual communication design education has always been, grasp the key problems of restricting the education quality and creative talents cultivation, in view of visual communication design field put forward the feasible implementing scheme of the comprehensive experimental course reform, the innovation of ideological concept education and teaching reform efforts in implementing the training plan, deal with digital art and design creative talents training, in the visual communication design in the process of curriculum reform, the comprehensive experiment in the formation of multi-channel way construction.

The development application visual communication design. Visual communication design is the design of the performance and convey to the audience through the media, it embodies the design 
characteristics, the field with the progress of science and technology development and application of the convey and expanding, and widely involved in other such as aesthetics, mechanics, psychology and so on, gradually formed a new areas associated with media and interaction design. Today's visual transmission design is not the single plane design, in the modern highly developed today, people to the requirement of visual communication design "is the true shape of an object - including psychology, physics and philosophy. "This sentence tell us new visual communication design, visual communication design in addition to its own development at the same time also to the field of other design, also make the visual communication design has become a professional in the design of the various disciplines. Such as the product design in industrial design, visual communication design of the logo and text elements into use in the product, at the same time also need to logo design, text, color the product and the product's logo, is one of the means of brand promotion, is to deepen the cognition to the enterprise brand, therefore, the development of visual communication design has been widely used.

To strengthen the visual communication design education curriculum design. Design sketch and color is the foundation, to master the basic knowledge of the perspective, light and shadow, color is very necessary, and help more vivid performance object, suitable for first year of college. Three, names the plane composition, color composition, three-dimensional construction. Planar formation mainly by dot, line, face image, using graphics to talk, to express the author's emotion; Use the color relations color composition, layout expressing artistic conception; Three-dimensional construction materials used all sorts of modeling of the imagination in accordance with the principle of certain artistic combination into a new three-dimensional object. These courses can develop the students' comprehensive aesthetic feeling, to lay the foundation for students to learn at the back of the professional course, also suitable for university in grade one. Format design of $2 \mathrm{~d}$, the multidimensional space arrangement of layout design; train the student to the object of performance as a whole and the control of local layout, suitable for sophomore students to learn. Interface design is in recent years the rise of a new course, it is necessary for digital media technology professional courses. Interaction design exhibition, interaction is dependent on the interface, since geared to the needs of users; you need through the communication interface to realize the user and the product and communication. Interface and system determines the success of the user experience, suitable for senior open last semester.

Pay attention to visual communication design major comprehensive experiment curriculum design. Improve teaching philosophy: from the cross of visual communication design and multidisciplinary, with development thinking, imagination, to cultivate design concept, create a diverse design methods and ways for the purpose of multidimensional performance. Make the student guide and emotional expression in the thought; find the rationalization of the visual space. In learning and creating build a wide range of knowledge structure, personalized, diversified, the rich connotation of globalization.

1) Rich visual language. Guide students to consciously observe the objective world, accumulate knowledge from life and find creative elements. Based on the professional basic course for training and the experience of formal language of visual thinking, asked the students when choosing visual elements to convey information, what should break through the general visual habit, tries to show the most rich content in the form of novel. "Graphic language" is the graphics, text, the three color visual elements as well as between the three elements of vivid expression of the aesthetic.

2 ) Integration of conveying medium. Visual communication design is a kind of communication, is a process of information communication, editor of the integration. Students in innovative design concept under the guidance, in different media, from the perspective of different design, discusses a variety of possibility of design, make a design on a new look. Plane media, electronic media, and display media space, need to be found in form of the exchange and communication between the breakthrough point, from the Angle of the audience to find the direction of the innovation. Visual transmission design is on the relationship between the media and interactive, looking for new media and traditional media exist differences in visual communication effect, to explore the intrinsic 
relationship between the visual media, strengthen the effect of visual communication in different media is discussed.

3) Optimize the course structure. The visual communication design comprehensive experimental courses as a whole, attaché's great importance to the project design in the important role of comprehensive experimental courses, in the teaching process of serration, scientific, multifaceted, with interesting and attractive subject design. Through various channels and media, tracking and collection of visual communication design at home and abroad the latest dynamic information, around the creative talents training, from the education idea, the curriculum goal, curriculum content, curriculum structure, the design of teaching activities, teaching management to improve the visual communication design comprehensive experimental course system. Outstanding comprehensive experiment teaching should be a dynamic, diverse, multi-dimensional, choose the knowledge in the context of globalization, to keep the necessary flexibility and openness in the teaching.

\section{Conclusion}

As a visual communication design to convey information for the purpose of art design categories, because of the property characteristics of traditional media, constantly breakthrough in the field of artistic expression. Should break the boundaries of time and space, visual communication design education field constantly expanding, expand the scope of its unique, set up a variety of digital media teaching means to reform the current teaching mode, improve teaching level. Under the new situation of the development of visual communication level and ability for the development of new media teaching way has brought new opportunities and challenges, shall be as a starting point, constantly improve the level of visual design teaching in the college, to adapt to the current development of social informatization.

\section{References}

[1] J. K. He, The development trend of visual communication design, Architectural decoration, 2008, vol. 6, pp. 65-69.

[2] G. T. Li, Visual communication design professional curriculum and explore, Leshan teachers college journal, 2012, vol. 3, pp.34-37.

[3] Y. B. Zhou, When new media art meets the visual communication design, Literary criticism, 2013, vol. 1, pp. 57-59.

[4] T. J. Wang, The modern visual communication forms and characteristics of digital media, Journal of Xi 'an academy, 2013, vol. 6, pp. 45-49.

[5] L. T. Liu, The new media of visual communication design, Journal of Nanjing college of art, 2012, vol. 7, pp. 13-17.

[6] F. T. Yu, Post-industrial era of visual communication design, The study of literature and art, 2015, vol. 12, pp. 27-22. 